\title{
The establishment of serum
} 25-hydroxyvitamin $D$ reference intervals in children aged 0-14 years in Zigong area, China

\author{
Jianhong $\mathrm{Yu}^{1 *}$, Xiaoping $\mathrm{He}^{1}$ and Shengwei Huang ${ }^{2}$
}

\begin{abstract}
Objective: To establish the reference interval of serum 25-hydroxyvitamin $\mathrm{D}(25(\mathrm{OH}) \mathrm{D})$ in apparently healthy children in Zigong, China, using an indirect method to provide a basis for proper clinical diagnosis and treatment.

Methods: A total of 1851 apparently healthy children of the Children's Health Care Department in Zigong First People's Hospital between January 2016 and December 2020 were included in the study. The Kolmogorov-Smirnov test was used to analyze the data for normality, and the non-normally distributed data were transformed into approximately normal distribution by Blom's normal rank transformation, and the transformed data were excluded from outliers by the quartile spacing method, and the data were stratified and analyzed according to sex, age, and season. The data were stratified according to sex, age, and season, and the area between the $2.5 \%$ and $97.5 \%$ percentile points was used as the reference interval.

Results: The serum 25(OH)D data were non-normally distributed. The data were normally distributed after Blom's normality rank transformation, and 92 cases of outliers were excluded from the transformed data according to the interquartile spacing method. The differences in serum $25(\mathrm{OH}) \mathrm{D}$ levels between sex were not statistically significant $(P>0.05)$, and there was no need to establish reference intervals based on sex. There was no statistically significant difference in serum 25-hydroxyvitamin D levels between winter and spring, and also no difference between summer and autumn $(P>0.05)$, and the levels were lower in winter-spring than in summer-autumn. Comparison between age groups showed that there was no statistically significant difference in serum $25(\mathrm{OH}) \mathrm{D}$ levels between the $<6$ months group and the $6 \sim 11$ months group, and between the $6 \sim 9$ years group and the $10 \sim 14$ years group $(P>0.05)$; serum $25(\mathrm{OH}) \mathrm{D}$ levels decreased with increasing age. There was an interactive effect of season and age group on $25(\mathrm{OH}) \mathrm{D}$ levels, and the corresponding reference intervals were established according to different seasons and age groups. In summer and autumn, the reference intervals of serum $25(\mathrm{OH}) \mathrm{D}$ for $<1$ year, $1 \sim 2$ years, $3 \sim 5$ years, and $6 \sim 14$ years were $39.86 \sim 151.43,31.54 \sim 131.65,22.05 \sim 103.75$, and $15.36 \sim 85.53 \mathrm{ng} / \mathrm{ml}$ and $24.42 \sim 144.20,31.54 \sim 131.65$, $16.80 \sim 165.68$, and $15.46 \sim 85.54 \mathrm{ng} / \mathrm{ml}$ in winter and spring, respectively.
\end{abstract}

Conclusion: Reference intervals for serum 25(OH)D in children of different seasons and ages in Zigong, China, were established to provide a reference for clinical disease diagnosis, treatment, and prognosis determination.

Keywords: 25-hydroxyvitamin D, Reference interval, Indirect method, Minors, Zigong area

*Correspondence: 893522692@qq.com

'Department of Clinical Laboratory, Zigong First People's Hospital, Zigong, China

Full list of author information is available at the end of the article permits use, sharing, adaptation, distribution and reproduction in any medium or format, as long as you give appropriate credit to the original author(s) and the source, provide a link to the Creative Commons licence, and indicate if changes were made. The images or other third party material in this article are included in the article's Creative Commons licence, unless indicated otherwise in a credit line to the material. If material is not included in the article's Creative Commons licence and your intended use is not permitted by statutory regulation or exceeds the permitted use, you will need to obtain permission directly from the copyright holder. To view a copy of this licence, visit http://creativecommons.org/licenses/by/4.0/. The Creative Commons Public Domain Dedication waiver (http://creativeco mmons.org/publicdomain/zero/1.0/) applies to the data made available in this article, unless otherwise stated in a credit line to the data. 
Vitamin D is a fat-soluble vitamin, its classical function is to regulate calcium and phosphorus homeostasis and enhance bone development. Various studies have shown that vitamin $\mathrm{D}$ deficiency leads to a variety of clinical disorders such as rickets, fractures, diabetes, asthma, and cardiovascular disease [1-3]. Vitamin D exists in the body mainly in the form of vitamin $\mathrm{D}_{2}$ and vitamin $\mathrm{D}_{3}$, both of which are converted to $25(\mathrm{OH}) \mathrm{D}$ in the liver via blood circulation and then to 1,25 -hydroxyvitamin $\mathrm{D}$ via the kidneys [4]. Among them, 25(OH)D is the main circulating form of vitamin $\mathrm{D}$ in the blood and is recognized as a reliable indicator to evaluate the nutritional status of vitamin $D$ in humans. Reference intervals for serum 25 $(\mathrm{OH}) \mathrm{D}$ in minors have been reported in Shanghai [5] and Quanzhou [6], China, but differences in vitamin D levels may exist in different regions with different levels of UV exposure [7]. The recommended vitamin D intake for children aged 0 to 14 years is $10 \mu \mathrm{g}$ per day (WS/T 578.4-2018 Dietary Nutrient Reference Intakes for Chinese Residents, http://www.nhc.gov.cn/wjw). Vitamin D use in school-age children is lower than in preschoolers [8]. Therefore, the author used the data available in the laboratory database to establish the reference interval of serum 25-hydroxyvitamin D in apparently healthy children in Zigong, China, using an indirect method. The aim was to provide a basis for proper clinical diagnosis and treatment.

\section{Material and methods}

\section{Research subjects}

Serum 25(OH)D test results were collected from 1911 children who were examined in the Children's Health Care Department of Zigong First People's Hospital from January 2015 to December 2020, and 26 cases with abnormal specimen status (such as hemolysis, lipemia, and jaundice) and 34 cases with abnormal blood, liver or kidney function results were excluded, and the final number of cases entered into this study was 1851 (1071 males and 780 females). The outliers were removed using the Turkey method. The study was approved by the Ethics Committee of Zigong First People's Hospital, and written informed consent was obtained from the guardian.

\section{Samples, instruments, and reagents}

Blood samples $(2 \mathrm{ml})$ were collected in all subjects after a fasting state of at least $8 \mathrm{~h}$, placed in a vacuum blood collection tube containing a procoagulant, centrifuged for $10 \mathrm{~min}$ at $5{ }^{\circ} \mathrm{C}$ with a relative centrifugal force of $3072 \times g$, separated the serum and finished the assay within $2 \mathrm{~h}$. The instrument is the CL-6000i fully automated chemiluminescence immunoassay analyzer (Shenzhen Myriad Biomedical Electronics Co., Ltd.), and the test reagents, calibrators, and quality control products are the supporting products of the instrument. Our laboratory uses Westgard multi-rules $\left(1_{3 S}, 2_{2 S}\right.$, and $\left.R_{4 S}\right)$ for internal quality control. The test project participated in the quality evaluation activities organized by the clinical laboratory center of the National Health Commission every year. The results were satisfactory, and the bias was acceptable. The coefficient of variation of the indoor quality control data for 25-hydroxyvitamin D was less than $8.33 \%$, and the bias of the inter-room quality evaluation data was less than $5.0 \%$.

\section{Establishment of the reference interval and statistical methods}

EXCEL spreadsheet was used to organize the data, and SPSS 26.0 software was used for statistical analysis of the data. Kolmogorov-Smirnov normality test was used to confirm normal distribution for totality of the data, and the non-normally distributed data were transformed into approximately normal distribution by Blom's normality rank transformation with SPSS 26.0 software and the normality of the transformed data was tested using Kolmogorov-Smirnov test. The outliers were removed using the Turkey method [9]. Data were analyzed by subgroup according to sex, season (spring: March-May; summer: June-August; autumn: September-November; winter: December-February) and age ( $<6$ months, $6 \sim 11$ months, $1 \sim 2$ years, $3 \sim 5$ years, $6 \sim 9$ years, 1014 years), and the Mann-Whitney $U$ test was used for comparisons between 2 groups and the Kruskal-Wallis $H$ test, one-way test in a general linear model for interaction between two groups, LSD test for two-way comparison, and the establishment of reference intervals when the difference between two groups was not statistically significant, and the reference intervals were expressed by the percentile method (P 2.5 to P 97.5). The difference was considered statistically significant at $P<0.05$.

\section{Results}

\section{Normality test and transformation}

After the Kolmogorov-Smirnov test, the serum 25-hydroxyvitamin D data showed skewed distribution. Blom's transformed data showed a normal distribution, as shown in Figs. 1 and 2.

\section{Outlier rejection}

The serum 25-hydroxyvitamin D data were sorted after an Excel spreadsheet. Outliers were removed using the Turkey method, the upper limit is the 75th percentile plus 1.5 times the interquartile range (IQR), and the lower limit is the 25th percentile minus 1.5 times the IQR. Excluding the outliers of 92 cases, the final number of cases entered into the study was 1759 . 


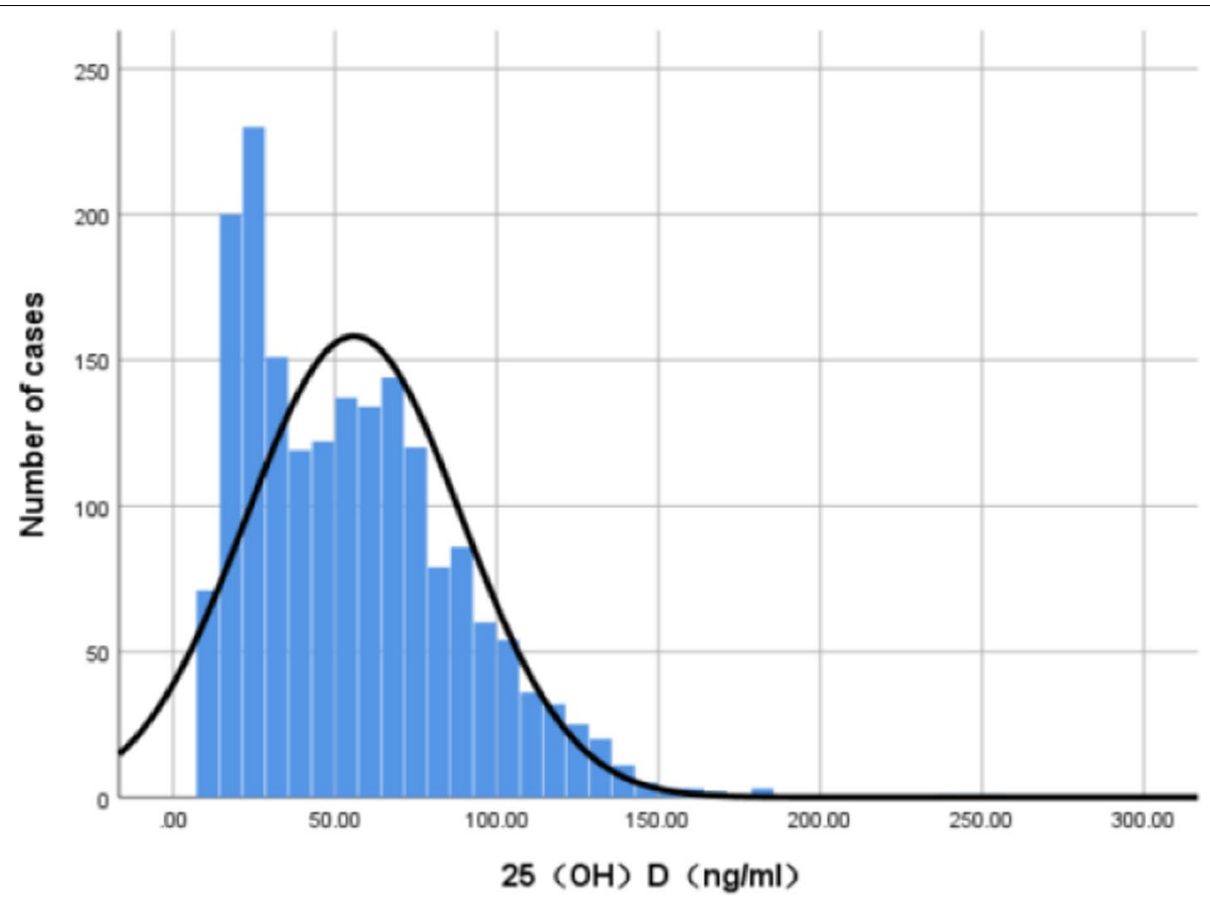

Fig. 1 Histogram of distribution of 25(OH)D

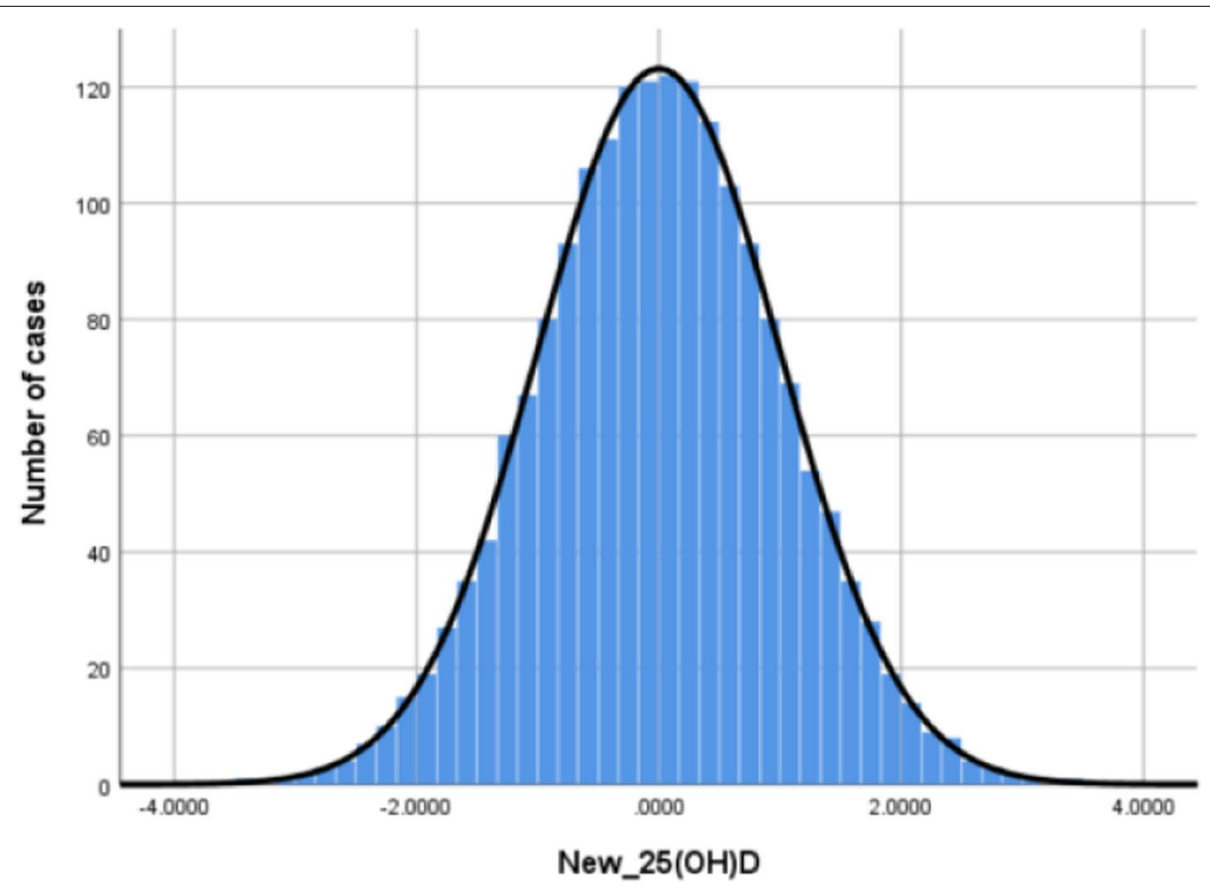

Fig. 2 Histogram of distribution of converted 25(OH)D

Serum 25-hydroxyvitamin D levels between sex

Serum 25-hydroxyvitamin D levels followed a normal statistical distribution in groups $<6$ months and $6 \sim 11$ months but skewed in groups $1 \sim 2$ years,
$3 \sim 5$ years, $6 \sim 9$ years, and 10 14 years (KolmogorovSmirnov test). There was no statistical difference in the composition ratio of sex between the different age groups $(P>0.05)$. There was no statistically significant difference 
Table 1 Comparison of serum 25(OH)D levels in the same age groups between sex

\begin{tabular}{lllll}
\hline Age & Sex & No & $\mathbf{2 5}(\mathbf{O H}) \mathbf{D}(\mathbf{n g} / \mathbf{m l})$ & P value \\
\hline$<$ 6 months & Male & 48 & $78.79 \pm 31.12$ & 0.125 \\
& Female & 26 & $90.12 \pm 27.75$ & \\
6 11 months & Male & 132 & $71.94 \pm 24.07$ & 0.320 \\
& Female & 101 & $72.68 \pm 26.56$ & \\
1 2 years & Male & 320 & $68.50(54.43,87.18)$ & 0.737 \\
& Female & 226 & $66.80(54.65,87.05)$ & \\
3 5 years & Male & 223 & $38.70(29.50,56.50)$ & 0.099 \\
& Female & 142 & $44.15(31.60,62.60)$ & \\
6 9 years & Male & 180 & $26.90(21.43,42.23)$ & 0.852 \\
& Female & 135 & $26.40(22.70,38.00)$ & \\
10 14 years & Male & 120 & $21.65(17.53,31.33)$ & 0.002 \\
& Female & 106 & $25.95(19.93,42.03)$ & \\
\hline
\end{tabular}

Table 2 Comparison of serum 25(OH)D levels between seasons, $\mathrm{M}(\mathrm{P} 25 \sim \mathrm{P} 75)$

\begin{tabular}{lll}
\hline Season & Number of cases & 25(OH)D $(\mathbf{n g} / \mathbf{m l})$ \\
\hline Spring & 598 & $48.10(26.58 \sim 73.65)$ \\
Summer & 526 & $57.25(33.50 \sim 80.03)$ \\
Autumn & 347 & $63.40(35.90 \sim 85.00)$ \\
Winter & 288 & $43.35(26.43 \sim 71.68)$ \\
$Z$ value & & 43.082 \\
$P$ value & & 0.000 \\
\hline
\end{tabular}

in serum 25-hydroxyvitamin $\mathrm{D}$ levels between sex in the same age groups $(P>0.05)$, except for group aged $10 \sim 14$ years (Table 1 ).

\section{Serum 25-hydroxyvitamin D levels between seasons}

The results of the Kruskal-Wallis $\mathrm{H}$ test showed that the differences in serum 25-hydroxyvitamin D levels between different seasons were statistically significant (Table 2). Two-by-two comparison between different seasons using Kruskal-Wallis one-way ANOVA (K-sample) multiple comparison selection all pairwise, listed in Table 3, indicates that there was no statistically significant difference in serum 25-hydroxyvitamin D levels between winter and spring, and also no difference between summer and autumn $(P>0.05)$.

Serum 25-hydroxyvitamin D levels among different age groups The difference in serum 25-hydroxyvitamin D levels between different age groups was statistically significant by the Kruskal-Wallis $\mathrm{H}$ test. By Kruskal-Wallis oneway ANOVA test, the differences in serum 25-hydroxyvitamin D levels between the $<6$ months group and the $6 \sim 11$ months group and between the $6 \sim 9$ years group and the $10 \sim 14$ years group were not statistically significant $(P>0.05)$. But the differences were statistically significant between groups $<1$ year, $1 \sim 2$ years, $3 \sim 5$ years, and $6 \sim 14$ years (Table 4 ).

\section{Reference intervals of serum 25-hydroxyvitamin D} in different seasons and age groups

In children aged $9 \sim 14$ years, although serum 25 -hydroxyvitamin $D$ levels were statistically.

different between the sexes, their $Z$ values were lower than $Z^{*}$ values and did not require the establishment of reference intervals based on sex (CLSI EP 28-A3C [10]). The seasons were divided into summer-autumn and winter-spring, and the ages were divided into groups aged $<1$ year, $1 \sim 2$ years, $3 \sim 5$ years, and $6 \sim 14$ years. There was an interaction of 25 -hydroxyvitamin $\mathrm{D}$ between different seasons and ages by general linear model test. Two-two comparisons showed that there was no statistically significant difference in serum 25-hydroxyvitamin $D$ levels between seasons in group aged $1 \sim 2$ years $(P>0.05)$, no seasonal grouping was required for reference interval establishment in the $1 \sim 2$ years group, and the reference range of serum 25-hydroxyvitamin $\mathrm{D}$ in children aged $1 \sim 2$ years was $31.54 \sim 131.65 \mathrm{ng} / \mathrm{ml}$. In contrast, seasonal differences existed between the remaining age groups, as shown in Table 5.

\section{Discussion}

Serum 25-hydroxyvitamin D is an important indicator of vitamin D levels. It is associated with human health status, and $25(\mathrm{OH}) \mathrm{D}$ levels are negatively associated with

Table 3 Paired comparison of serum 25(OH)D by season

\begin{tabular}{|c|c|c|c|c|c|}
\hline Season-Season & Test statistics & Standard error & $\begin{array}{l}\text { Standard test } \\
\text { statistics }\end{array}$ & $P$ value & Adjusted $P$ value \\
\hline Winter-Spring & 33.510 & 36.431 & 0.920 & 0.358 & 1.000 \\
\hline Winter-Summer & 149.602 & 37.232 & 4.018 & 0.000 & 0.000 \\
\hline Winter-Autumn & 211.384 & 40.488 & 5.221 & 0.000 & 0.000 \\
\hline Spring-Summer & -116.092 & 30.362 & -3.824 & 0.000 & 0.001 \\
\hline Spring-Autumn & -177.875 & 34.277 & -5.189 & 0.000 & 0.000 \\
\hline Summer-Autumn & -61.782 & 35.127 & -1.759 & 0.079 & 0.472 \\
\hline
\end{tabular}


Table 4 Comparison of serum 25(OH)D levels between different age groups, $\mathrm{M}(\mathrm{P} 25 \sim \mathrm{P75})$

\begin{tabular}{lll}
\hline Age group & Number of cases & 25(OH)D $(\mathbf{n g} / \mathbf{m l})$ \\
\hline$<6$ months & 74 & $81.60(63.88 \sim 101.50)^{\mathrm{a}}$ \\
$6 \sim 11$ months & 233 & $85.40(66.10 \sim 109.00)^{\mathrm{a}}$ \\
$1 \sim 2$ years & 546 & $68.20(54.50 \sim 87.13)$ \\
$3 \sim 5$ years & 365 & $40.70(30.50 \sim 59.35)$ \\
$6 \sim 9$ years & 315 & $26.70(22.30 \sim 41.50)^{\mathrm{b}}$ \\
$10 \sim 14$ years & 226 & $23.10(18.70 \sim 32.63)^{b}$ \\
$Z$ value & & 828.836 \\
$P$ value & & $0.000^{*}$ \\
\hline
\end{tabular}

${ }^{a}$ No statistical difference between groups aged $<6$ months and $6 \sim 11$ months.

${ }^{\text {b }}$ No statistical difference between groups aged $6 \sim 9$ years and $10 \sim 14$ years.

*Statistical difference between age groups overall.

all-cause mortality and stroke risk in elderly Chinese [11, 12]. Higher levels of $25(\mathrm{OH}) \mathrm{D}$ are associated with lower overall cancer risk [13]. Higher levels of $25(\mathrm{OH}) \mathrm{D}$ are also associated with lower all-cause mortality and cardiovascular disease mortality in patients with diabetes [14]. However, vitamin D insufficiency or deficiency is relatively common in Chinese children and adolescents [15] and postmenopausal women [16]. Vitamin D levels can be increased by sunlight exposure or oral vitamin D supplements. Vitamin D levels can be increased by sunlight exposure or oral vitamin D supplements. However, oversupplementation can also be a health threat, and the literature [17] reports that higher lifetime levels of $25(\mathrm{OH})$ $\mathrm{D}$ are associated with an increased risk of leukoaraiosis. Therefore, proper assessment of serum 25(OH)D levels is of great value for health status, disease diagnosis, and prognostic assessment.

Reference intervals are criteria for assessing health status, disease diagnosis, and prognosis. Most clinical decision-making processes are based on the information provided by laboratory reports. Therefore, providing reliable reference intervals is a fundamental task of clinical laboratories [18]. Currently, the reference intervals used in clinical laboratories are mainly derived from the instructions provided by reagent manufacturers, national clinical test protocols, or literature. However, the inconsistency of measurement results among laboratories is prominent due to different testing systems, different testing methods, different reagent manufacturers, and different geographical regions. Therefore, the reference intervals established by each laboratory according to the local population are more valuable for guiding the diagnosis, disease monitoring, and prognosis of diseases. However, the inconsistency of measurement results among laboratories is prominent due to different testing systems, different testing methods, different reagent manufacturers, and different geographical regions. Therefore, the reference intervals established by each laboratory according to the local population are more valuable for guiding the diagnosis, disease monitoring, and prognosis of diseases.

The establishment of reference intervals by the direct method is recommended by the CLSI EP 28-A3C document [10]. However, the direct method has some disadvantages, such as it requires a lot of human and material resources. Also, children may be limited by ethical restrictions, elderly people may be limited by chronic diseases or medication use. Therefore, establishing reference intervals by the direct method is difficult for most laboratories. With the development of information technology, the indirect establishment of reference intervals through a large amount of data in laboratory information systems is accepted by the EP28-A3C document. In this study, the reference intervals for serum $25(\mathrm{OH}) \mathrm{D}$ in children in the Zigong region of China were established by statistical analysis based on the results of serum $25(\mathrm{OH})$ $\mathrm{D}$ tests in apparently healthy children in the last 5 years. Serum 25(OH)D levels in children in the Zigong area did not differ statistically significantly between sex, consistent with Xiao Long-necked [19] and others, and were lower in winter and spring and higher in summer and autumn, due to less sunlight and lower UV exposure and reduced skin synthesis in winter and spring than in summer and autumn. 25-hydroxyvitamin D levels are highest in children under 1 year of age and their levels decrease with increasing age, as also observed in Hangzhou, China [20]. The reason for this may be that children under the age of 1 year are mainly fed on breast milk or formula. Also, this group of children will routinely take vitamin

Table 5 Comparison of serum 25(OH)D levels between seasons in the same age group $(\mathrm{ng} / \mathrm{ml})$

\begin{tabular}{|c|c|c|c|c|c|c|c|c|c|c|c|c|c|}
\hline \multirow[t]{2}{*}{ Age group } & \multicolumn{6}{|c|}{ Summer-Autumn } & \multicolumn{6}{|c|}{ Winter-Spring } & \multirow[t]{2}{*}{$P$ value } \\
\hline & $N$ & P2.5 & P25 & P50 & P75 & P97.5 & $\mathbf{N}$ & P2.5 & P25 & P50 & P75 & P97.5 & \\
\hline$<1$ year & 172 & 39.86 & 71.18 & 90.40 & 114.00 & 151.43 & 135 & 24.42 & 58.40 & 80.50 & 95.50 & 144.20 & 0.002 \\
\hline $1 \sim 2$ years & 268 & 34.70 & 54.55 & 68.90 & 87.20 & 134.38 & 278 & 30.65 & 54.38 & 67.40 & 87.03 & 131.05 & 0.523 \\
\hline $3 \sim 5$ years & 169 & 22.05 & 32.35 & 48.30 & 66.05 & 103.75 & 196 & 16.80 & 28.13 & 37.90 & 52.18 & 165.68 & 0.000 \\
\hline $6 \sim 14$ years & 264 & 15.36 & 21.85 & 27.5 & 55.90 & 85.53 & 277 & 15.46 & 22.00 & 27.60 & 56.10 & 85.54 & 0.000 \\
\hline
\end{tabular}


D supplementation by oral means and have better compliance with oral vitamin D. As their age increases, children's physiological needs for vitamin D gradually increase, but vitamin D supplementation is insufficient. Given the interaction of different seasons and ages on serum 25(OH)D levels, this study established reference intervals for serum $25(\mathrm{OH}) \mathrm{D}$ in children of different seasons and age groups (Table 5), and serum 25(OH)D levels were higher in children aged $6 \sim 14$ years than in Iranian children [21], which may be due to different ethnic groups and different lifestyle habits. The manufacturer's reagent instructions $(>30 \mathrm{ng} / \mathrm{ml}$ as adequate, $<20 \mathrm{ng} / \mathrm{ml}$ as deficient, and $20-30 \mathrm{ng} / \mathrm{ml}$ as insufficient) referred to the reference interval in this laboratory, the percentage of 25(OH)D insufficiency or deficiency in apparently healthy children amounted to $25.58 \%$. If the health industry-standard (WS/T 677-2020 Screening method for vitamin D deficiency in human population, http:// www.nhc.gov.cn/wjw) is used as the judgment standard, the rate of $25(\mathrm{OH}) \mathrm{D}$ insufficiency or deficiency is $7.56 \%$, which is mainly distributed in the population aged $6 \sim 14$ years old, and the possible reasons are: (1) children in this age group are mostly primary or junior high school students, with increased academic tasks and reduced outdoor sunlight exposure related; (2) children above 6 years of age have increased physiological needs but reduced or missing oral vitamin D preparations. Therefore, time for outdoor exercise should be ensured for primary and secondary school students, serum 25(OH)D levels should be monitored regularly, and vitamin D preparations should be supplemented promptly for those with insufficient vitamin $\mathrm{D}$ levels to ensure that their vitamin $\mathrm{D}$ is maintained at adequate levels.

In conclusion, this study established reference intervals for serum 25(OH)D in children of different seasons and ages in Zigong, China. When determining the status of vitamin D levels in children, child health practitioners should combine this reference interval with relevant health industry standards to make comprehensive judgments and correct conditions of vitamin D overdose, deficiency, or lack in a timely manner to promote children's health.

\section{Abbreviation}

25(OH)D: 25-Hydroxyvitamin D.

\section{Acknowledgements}

None

\section{Author's contributions}

Jianhong Yu made substantial contributions to the conception and design of the manuscript. Shengwei Huang made substantial contributions to the construction of the measurement protocol. Jianhong Yu and Xiaoping He have been involved in the statistical data analysis. The authors read and approved the final manuscript.

\section{Funding}

No funding was obtained for this study. This research did not receive any specific grant from funding agencies in the public, commercial, or not-forprofit sectors. Open Access funding enabled and organized by Zigong First People's Hospital.

\section{Data availability}

The datasets supporting the conclusions of this article are included within the article.

\section{Declarations}

\section{Ethics approval and consent to participate}

This study was approved by the Ethics Committee of Zigong First People's Hospital, China. All participants' guardians signed an informed consent form in advance.

\section{Consent for publication}

Not applicable.

\section{Competing interests}

The authors declare that they have no competing interests.

\section{Author details}

${ }^{1}$ Department of Clinical Laboratory, Zigong First People's Hospital, Zigong, China. ${ }^{2}$ Department of Nuclear Medicine, Zigong First People's Hospital, Zigong, China.

Received: 30 June 2021 Accepted: 27 September 2021

Published online: 06 October 2021

\section{References}

1. Izzo M, Carrizzo A, Izzo C, Cappello E, Cecere D, Ciccarelli M, lannece P, Damato A, Vecchione C, Pompeo F. Vitamin D: not just bone metabolism but a key player in cardiovascular diseases. Life (Basel). 2021;11(5):452.

2. Litonjua AA. Vitamin D and childhood asthma: causation and contribution to disease activity. Curr Opin Allergy Clin Immunol. 2019;19(2):126-31.

3. Sassi F, Tamone C, D'Amelio P, Vitamin D. Nutrient, hormone, and immunomodulator. Nutrients. 2018;10(11):1656.

4. Carter GD. Accuracy of 25-hydroxyvitamin D assays: confronting the issues. Curr Drug Targets. 2011;12(1):19-28.

5. Gao Zh, Xu M, Yuan M, Xu J. Preliminary investigation for the reference intervals of serum 25-hydroxyvitamin D among minors in Shanghai. Laboratory Medicine. 2017;32(4):280-3 ((in Chinese)).

6. Zhu Q, Chen J, Li W, Huang B, Su Zh. Analysis of 25 hydroxyvitamin D levels in children aged 0-12 years in Quanzhou area[J]. Chin J Appl Clin Pediatr. 2018;33(11):842-5 ((in Chinese)).

7. Jiang W, Wu DB, Xiao GB, Ding B, Chen EQ. An epidemiology survey of vitamin D deficiency and its influencing factors. Med Clin (Barc). 2020;154(1):7-12.

8. Wang JZ, Zhang YR, Xue Y, Zhao A, Zheng YD, Zhang YM, Wang PY. Intake of supplemental vitamin and mineral of Chinese children aged $3 \sim 12$ years old. Chinese Journal of Child Health Care, 1015, 23(6): 584-587, 591 (in Chinese)

9. Tukey JW. 1977 Exploratory data analysis. reading [M]. New York: AddisonWesley, 506-506.

10. Defining, Establishing, and Verifying Reference Intervals in the Clinical Laboratory; Approved Guideline-Third Edition. CLSI document EP28-A3C ed Wayne, PA, USA: CLSI (Clinical Laboratory Standards Institute). 2010.

11. Jin $X$, Xiong S, Ju SY, Zeng Y, Yan LL, Yao Y. Serum 25-hydroxyvitamin D, albumin, and mortality among Chinese older adults: a population-based longitudinal study. j Clin Endocrinol Metab. 2020;105(8):dgaa349.

12. Shi H, Chen H, Zhang Y, Li J, Fu K, Xue W, Teng W, Tian L. 25-Hydroxyvitamin D level, vitamin D intake, and risk of stroke: a dose-response metaanalysis. Clin Nutr. 2020;39(7):2025-34.

13. Budhathoki S, Hidaka A, Yamaji T, et al. Japan Public Health Center-based Prospective Study Group. Plasma 25-hydroxyvitamin D concentration and 
subsequent risk of total and site-specific cancers in Japanese population: large case-cohort study within Japan Public Health Center-based Prospective Study cohort. BMJ. 2018;360:k671.

14. Wan Z, Guo J, Pan A, Chen C, Liu L, Liu G. Association of serum 25-hydroxyvitamin $D$ concentrations with all-cause and cause-specific mortality among individuals with diabetes. Diabetes care. 2021;44(2):350-7.

15. Zou Y, Zhang R, Huang L, Su D, He M, Fang Y, Zhao D, Wang W, Han D. Sociodemographic disparity in the nutritional status. Eur I Clin Nutr. 2021;75(2):307-13

16. Joh HK, Hwang SS, Cho B, Lim CS, Jung SE. Effect of sun exposure versus oral vitamin D supplementation on serum 25- hydroxyvitamin D concentrations in young adults: a randomized clinical trial. Clin Nutr. 2020:39(3):727-36.

17. Zhong Z, Su G, Du L, Zhou Q, Li F, Chi W, Liu S, Zhang M, Zuo X, Yang P. Higher 25-hydroxyvitamin $D$ level is associated with increased risk for Behçet's disease. Clin Nutr. 2021;40(2):518-24.

18. Katayev A, Balciza C, Seccombe DW. Establishing reference intervals for clinical laboratory test results: is there a better way? there a better way? Am J Clin Pathol. 2010;133(2):180-6.
19. Xiao X, He J, Li Y, Han Z, Hu Sh, Huang H. Analysis of total calcium and 25-hydroxyvitamin D of children in Panyu. Guangzhou Lab Med. 2015;30(7):694-6. (in Chinese)

20. Chen Z, LV X, Hu W, Qian X, Wu T, Zhu Y. Vitamin D status and its influence on the health of preschool children in Hangzhou. Front Public Health. 2021;9:675403.

21. Qorbani M, Mahdavi Gorabi A, Ejtahed HS, Namazi N, Khoramdad M, Heshmat R, Kazemian E, Kelishadi R. Percentile values for serum levels of vitamins A and D in Iranian children and adolescents: The CASPIAN-Y study. Nutrition. 2021;90:111307.

\section{Publisher's note}

Springer Nature remains neutral with regard to jurisdictional claims in published maps and institutional affiliations.
Ready to submit your research? Choose BMC and benefit from:

- fast, convenient online submission

- thorough peer review by experienced researchers in your field

- rapid publication on acceptance

- support for research data, including large and complex data types

- gold Open Access which fosters wider collaboration and increased citations

- maximum visibility for your research: over $100 \mathrm{M}$ website views per year

At BMC, research is always in progress.

Learn more biomedcentral.com/submissions 